\title{
IMMUNOLOGY OF LIVER DISEASE
}

\author{
David R. Triger \\ Department of Medicine. Floor M. Hallamshire Hospital. Sheffield. England.
}

\section{SUMMARY}

There appears to be strong evidence to suggest that the liver plays an important role in the normally functioning immune system and in disorders involving damage to the liver disturbances in the immunological parameters are frequently found. In the light of our current knowledge, however, it is not clear whether these disturbances occur secondary to this liver damage or whether some or all of them provide the initiating stimulus for the liver damage or even the stimulus which potentiates the development of chronic liver disease. A greater understanding of these factors is necessary if we are to develop more effective therapy for chronic hepatic disorders.

\section{INTRODUCTION}

The last twenty years have seen an enormous expansion in our knowledge of liver disease and, quite co-incidentally, there have been major advances in immunology over the same period. The possible. importance of immune mechanisms in disorders of the liver is prompted by a number of observations:

1. The liver is anatomically the largest single organ in the reticulo-endothelial system.

2. Abnormalities in both cellular and humoral immunity are commonly found in acute and chronic liver disease.

3. Primary biliary cirrhosis and some kinds of chronic active hepatitis are often associated with disorders which are thought to be auto-immune.

4. Certain conditions which are thought to be immunologically mediated (e. g. arthritis, arthralgia, skin rashes) are associated with several forms of liver disease.

5. No satisfactory explanation has been found for the observation that only a proportion of patients are sensitive to the effects of certain drugs and toxins and immunological mechanisms have been suggested as possible causes.

6. Therapeutic agents which affect immunological mechanisms appear to have some beneficial effect on certain liver disorders.

During recent years an immense amount of work has been published in an attempt to highlight and explain these phenomena. In this article I shall attempt to review some of this data.

\section{Immunologecal function of the liver}

The liver can be considered as the largest single organ in the reticulo-endothelial system. The hepatic R.E. system is made up of cells lining the liver sinusoids which are traditionally classified as either endothelial cells or Kupffer cells. Although morphologi- 
cally distinct (Wisse, 1977), functional differences between these two groups are often not so clear cut. At any given moment only a minority of these cells are phagocytic but it seems probable that other cells can be stimulated by external stimuli to become active and perform a váriety of different functions. These cells are probably derived from bone marrow, spleen and peripheral blood and can be recruited from these sites when liver damage occurs. Under normal conditions these liver macrophages are sessile and have a very slow. turnover. Mitosis is rarely seen although it can be induced experimentally by agents such as Zymosan. The main cellular component of other organs in the reticuloendothelial system (e.g. spleen and lymph node) is the lymphocyte which is not found in the normal undamaged liver.

Because of its strategic anatomical position between the gastro-intestinal tract and the systemic circulation, the liver can be considered as a filter of exogenous material absorbed from the gastro-intestinal tract into the portal venous system. Experiments using cell-free mice (Sell and Fahey, 1964) have shown that intestinal flora provide the major stimulus to gamma globulin production as a result of the absortion of bacteria or bacterial antigens from the gut into both lymphatic and portal venous systems. This is supported by experiments in which radio-active labelled antigens have been introduced into the gastro-intestinal tract and subsequently demonstrated in the liver (Ravin et al, 1960) as well as in both lymph and blood (Warshaw et al, 1974). Once antigens are absoirbed into the portal venous system they must pass through the hepatic sinusoids before gaining access to the general circulation and certainly particulate antigens such as sheep erythrocytes (Triger et al, 1973) and Salmonella adelaide (Thomas et al, 1973) can be trapped there in significant amounts. In contrast to the spleen which phagocytoses antigens and processes them for antibody production, the liver appears to process and degrade antigens very rapidly and effectively without production of antibody (Franzl, 1972). This may be related to the observation that lymphoid cells are not found in the normal liver. It may not be true in patients with chronic liver disease where immunoglobulins can be readily demonstrable in the liver but there is no data on this.

The effect of filtering antigens from the portal vein will be to reduce the amount of such material available to the antibody producing components elsewhere in the reticulo-endothelial system. Thus, repeated immunisation of rats by injecting small amounts of sheep erythrocytes into the portal vein results in a significantly lower antibody production compared with similar immunisation via the inferior vena cava (Triger et al, 1973). Damage to the liver such as by blocking the reticulo-endothelial system with colloidal carbon (Souhami, 1972) or damage by carbon tetrachloride (Triger and Wright, 1973) will abolish this difference and result in increased antibody production.

A number of workers have shown that oral feeding of antigen can lead to the development of a state of tolerance to these particular substances (Swarbrick et al, 1979). Cantor and Dumont, (1967) have suggested that this may be due to the function of the liver. Using dogs fed with dinitrochlorobenzene they were able to abolish this response by subjecting the animals to a porta caval shunt before the start of the experiment. Although the phenomenon of immunological tolerance is poorly understood it seems likely to play an important role in the protection of the body against foreign antigens.

The liver macrophages have many other important functions in addition to the ability to phagocytose particulate matter. They play an essential part in $T$ and $B$ lymphocyte interaction which is undoubtedly very important in the pathogenesis of many liver disorders. They are also important in the mechanisms of tissue damage repair. The natural process of aging of the Kupffer cell is that it bećomes converted to a giant cell, so it seems likely that clues to the pathogenesis of granulomatous liver disease will be found in further study of the macrophage system. 


\section{IMMUNITY IN LIVER DISEASE}

Disturbances in both cellular and humoral immunity are commonly found in both acute and chronic liver disease. These disturbances are so common that it is difficult to assess their significance particularly as they tend to be rather non-specific. Some, however, appear to be rather more specific and serve as useful markers for the identification of certain disorders.

\section{Disturbances in B cell function (Humoral antibody production)}

Since the early days of serum protein electrophoresis it has been recognised that chronic liver disease is commonly accompanied by a reversal in the albumin/globulin ratio and an absolute increase in the serum globulin. Later work recognised that this globulin increase was confined almost entirely to the gamma globulin fraction and in particular to serum immunoglobulins. This increase is usually polyclonal although very occasionally monoclonal gammopathy can be found. Particular patterns of immunoglobulin abnormalities tend to be associated with different disorders. Elevations in IgG are characteristic of chronic active hepatitis while the majority of patients with primary biliary cirrhosis have increased IgM levels. High IgA levels are found in association with alcohol ingestion but they are not related to the type or severity of liver disease. The elevated globulin is due to increased synthesis (Havens et al, 1954) and this is supported by the observation that patients with cirrhosis have an increased capacity to produce circulating antibodies to administered antigens such as diphtheria toxoid and tetanus antitoxin (Havens et al, 1957).

Since the globulin production in the experimental animal is largely stimulated by antigens in the gastro-intestinal tract the hyperglobulinaemia seen in liver disease may at least in part be due to the failure of this organ to sequester such absorbed antigens. Thus, Protell et al (1971) have demonstrated increased anti-Salmonella agglutinins in patients with chronic active hepatitis. Similarly increased antibody titres to intestinal tract organisms and dietary proteins have been demonstrated in cirrhosis and chronic active hepatitis (Bjorneboe et al, 1972; Triger et al, 1972). Serial studies of E. Coli antibody titres in patients with acute viral hepatitis show that at the onset of hepatitis the antibody titres are normal but over the next few weeks they rise to a peak only to fall steadily back to normal over a period of months following the patient's recovery. In contrast antibodies to Haemophilus influenzae (a non intestinal tract organism) are normal throughout the acute hepatitis; an observation which argues against this being a non-specific response. This was explained by the hypothesis that the intact liver allowed only a small amount of antigen to enter the systemic circulation resulting in production of small amounts of antibody. Following damage to the liver this amount of antigen increase considerably and after a period of a week or two led to a consequent increase in antibody production. Then, as the liver returned to normal function, increased quantities of antigen could no longer bypass it and the antibody levels fell gradually back to normal, the rate of fall being dependent on the half-life of the antibody. Several different hepatic mechanisms might account for the bypassing of the liver by such antigens. The hepatic macrophages may be so overwhelmed during acute inflammation in dealing with local cell necrosis that they are unable to handle the antigens presented to them via the liver sinusoids, or alternatively the liver macrophages themselves may be destroyed by the acute necrosis. The latter seems unlikely since there is no good evidence of severe macrophage depletion in acute liver damage. Intrahepatic shunting of blood is now being recognised as an increasingly important haemodynamic consequence of liver disease. The highest antibodies to $\mathrm{E}$. coli are found in alcoholic liver disease and there is recent evidence to suggest that in this form of disease intrahepatic 
shunting may be more significant than in cirrhosis of other aetiologies, (Triger et al, 1979). Finally in patients with established portal hypertension the presence of a collateral circulation which completely bypasses the liver is already well recognised.

These explanations fail to account for the grossly elevated antibody titres to certain viruses, notably measles, rubella and cytomegalovirus which are found in patients with chronic active hepatitis (Triger et al, 1974). Although elevated titres to CMV are also found in alcoholic cirrhosis the high measles and rubella antibody levels seem to occur only in that type of chronic active hepatitis associated with auto-antibodies and with histo-compatibility antigens A1 and B8. Such antibody titres are not found in these patients in the absence of liver disease and there appears to be no cross reaction between the autoantibodies and the viral antibodies. No adequate explanation has yet been offered for these observations.

The increased antibody production in patients with liver disease occurs throughout the body as shown by the finding of splenomegaly and lymph node enlargement in most patients with chronic liver disease. Immunofluorescent studies suggest that these are indeed the site of increased antibody concentration. Immunoglobulins can also be found in the livers of such patients. Whether this reflects the site of production or merely a site of deposition of globulins is not known.

Several other factors may contibute to the hyperglobulinaemia. The high viral antibodies in chronic active hepatitis could be related to release of viral antigens sequestered in the liver, analogous to the measles infection which accompanies sub-acute sclerosing panencephalitis which leads to comparably high antibody titres to measles virus alone. Endotoxin is a potent B cell mitogen which is found in the circulation of some patients with liver disease and this may stimulate antibody production. Products of liver cell breakdown, such as nucleic acids may act as an adjuvant to antibody synthesis. B cell hypereactivity may occur to compensate for the depressed $T$ cell function which is generally found in liver disease. It seems unlikely that any single factor predominates in acute or chronic liver disease but different factors may play varying roles. It remains to be seen whether hyperglobulinaemia has any clinical or prognostic significance.

\section{Autoantibodies}

Interest in tissue autoantibodies in hepatic and other disorders was first stimulated by Gajdusek (1957) who reported complement fixing antibodies in serum of patients with liver disease against an extract of normal human liver. Although most of these have been shown to be neither organ nor species specific a number have been shown to be useful clinical markers in the investigation of liver disorders.

\section{Antinuclear antibody}

This was first described by Haserick et al (1950) in the serum of patients with systemic lupus erythematosus. This antibody is directed against several nuclear constituents notably deoxyribonucleic protein, ribonucleic acid and nucleo-histones. The Antinuclear factor can be demonstrated by a variety of immunological techniques including indirect immunofluorescence, latex precipitation, tanned red cell agglutination and complement fixation. Because of the heterogenous nature of the antigen against which they are directed, different immunofluorescent patterns may be produced by antinuclear antibodies and these have been variously described as speckled, difuse or homogenous. Initial hopes that these patterns might be of value in clinical diagnosis have unfortunately not been substantiated. Their diagnostic value lies in the fact that although they are 
found in systemic lupus erythematosus and a number of collagen disorders their presence in liver disease is restricted to certain forms of chronic active hepatitis and primary biliary cirrhosis in contrast to other forms of liver disease (Doniach at al, 1966). More recently antinuclear antibodies have been found in an increasing number of drug associated liver disorders, notably those related to methyldopa, oxyphenisatin and isoniazid. Antinuclear antibodies are also found occasionally in the normal population but usually in only low titre. The frequency of the antibody in the other disorders is rather variable, much of the conflict arising from the difficulty in defining positivity. Antibody titres of 1:10 or less are accepted by most workers as unimportant while titres equal to or greater than 1:80 are usually considered to be highly significant. IgG class antibodies are more commonly associated with pathological disease than IgM antibodies.

\section{Anti DNA antibodies}

Antibodies to double-stranded DNA were originally described as being specific for SLE but more recent work has shown that they are commonly found in the serum of patients with all forms of acute and chronic liver disease (Kingham et al, 1978). Although the highest titres are found in $\mathrm{HBsAg}$ negative active chronic hepatitis, high titres are also found in $\mathrm{HBsAg}$ positive disease of all degrees of activity. The antigenic stimulus for these antibodies is not clear. It may be secondary to hepatic or viral specific DNA. Alternatively antibodies to DNA can be induced experimentally in rabbits by repeated immunisation with bacterial lipopolysaccharide (Fournié et al, 1974) suggesting that the production of these antibodies could be a response to exogenous antigen in some way analogous to the E. coli antibody production.

\section{Smooth muscle antibody}

Although first described in patients with chronic active hepatitis Johnson et al, $1965)$ this autoantibody has been reported in many disorders, both hepatic and nonhepatic. Indirect immunofluorescence remains the sole means of detection and by this technique smooth muscle antibody may stain the myosin of bile canaliculi, renal glomeruli and thyroid epithelial cells. Recent studies have suggested that the antibody is directly produced against actin (Lidman et al, 1976). Two groups of smooth muscle antibodies can be recognised. Low titre antibody of IgM type is frequently found transiently in the serum of patients with various viral infections including viral hepatitis and infectious mononucleosis. It may also be found in alcoholic liver disease of all varieties and in most other forms of chronic liver disease where it is of no diagnostic or prognostic value. In contrast high titre IgG smooth muscle antibody is a feature of auto-immune chronic active hepatitis where it is often associated with the presence of high titre anti nuclear antibody and in association with histocompatibility antigens A1, B8 and Dw3 (see below).

\section{Mitocbondrial antibody}

This autoantibody is of considerable clinical importance because of its frequent occurrence in primary biliary cirrhosis and its rarity in other disorders. Klatskin and Kantor (1972), in a detailed study of 188 patients with this condition, found the antibody in $84 \%$ of the patients and showed it to provide useful confirmatory evidence of primary biliary cirrhosis when liver biopsy findings were consistent with diagnosis. Both they and other authors have reported the mitochondrial antibody in the serum of 
$10-20 \%$ of patients with chronic active hepatitis and this probably reflects some common aetiological relationship between the two disorders. Earlier reports of mitochondrial antibodies in halothane-associated hepatitis (Rodriguez et al, 1969) and prolonged extrahepatic obstruction (Lam et al, 1972) have not been confirmed and although the antibody is occasionally seen in patients with acute hepatitis it is usually transient and present in low titre. Titres of less than 1:40 are generally regarded as non-specific. Above this, however, there appears to be no correlation between the height of the titre and any clinical or prognostic features. There appears to be an increased incidence in patients with connective tissue disorders and in the relatives of patients with primary biliary cirrhosis (Walker et al, 1972). Although familial cases of P.B.C. have been reported (Tong et al, 1977) most relatives show minor non specific abnormalities in the liver and they do not usually progress to overt primary biliary cirrhosis. The autoantibody may merely represent a marker of potential auto-immune disease.

The antimitochondrial antibody is detectable by direct immunofluorescence or by complement fixation and electron microscopy studies have shown that it is directed against the inner mitochondrial membrane (Bianchi et al, 1973). The antibody is neither organ-specific nor species-specific and there is nothing to suggest any association between its localisation and the pathogenesis of primary biliary cirrhosis.

\section{Bile canalicular antibody}

This liver-specific antibody has been reported in the serum of some patients with chronic active hepatitis and primary biliary cirrhosis but it has not proved useful as a diagnostic tool. As mentioned earlier, immunofluorescent staining of bile canaliculi may be seen with sera containing strongly positive antibodies to smooth muscle.

\section{Liver cell membrane antibody}

Meyer zum Büschenfelde et al, 1972 have purified and characterised a liver specific protein (LP-2) which, on repeated injection into rabbits, can produce the histological lesion of chronic active hepatitis. Using an immunofluorescent technique this group has been able to demonstrate immunoglobulin binding to isolated hepatocytes when incubated with sera from patients with liver disease. Two different fluorescent patterns have been recognised; a linear pattern in $\mathrm{HBsAg}$ negative auto-antibody positive chronic active liver disease and a granular pattern in $\mathrm{HBsAg}$ positive chronic active liver disease (Meyer zum Büschenfelde, 1979). These patterns, which are thought to be due to liver membrane antibodies, have been reported in chronic active hepatitis, acute viral hepatitis and inactive cirrhosis (Tage-Jensen et al, 1977). There was no correlation with the presence of other autoantibodies and no apparent differences between groups with or without the antibody. Other liver specific proteins have also been reported (Sugamara and Smith, 1976; Arakawa et al, 1976). These are immunologically distinct from LP-2 but their role in the pathogenesis of liver disease has yet to be established.

\section{Otber autoantibodies}

Anti-gammaglobulin antibodies (rheumatoid factors) are frequently found in all forms of chronic liver disease. Liver and kidney microsomal antibodies are occasionally found in a number of liver disorders, notably active chronic hepatitis occurring in young patients (Rizzetto et al, 1973) and they may even represent a clinical sub-group of this disorder. Wassermann-type reactions associated with cardiolipin antibodies are occasio- 
nally seen in lupoid hepatitis, but they are of no clinical significance. Autoantibodies to thyroid and gastric parietal cells are found with increased frequency in patients with lupoid hepatitis, but the incidence in other types of liver disease is unremarkable. None of the autoantibodies so far described has proved to be a reliable guide to prognosis or to response to therapy in any forms of liver disease.

Using immunofluorescent and immunoperoxidase techniques, complement and immunoglobulins can be detected within the liver of patients with a variety of disorders although, as mentioned earlier, such abnormalities are not found in the undamaged liver. It is not known whether these substances are synthesized within the liver or merely deposited there from elsewhere. The type or nature of the immunoglobulin deposition does not appear to correlate with any clinical or histological parameters of liver disease.

\section{DISTURBANCE IN T CELL FUNCTION}

Cell mediated immunity appears to be depressed in most forms of acute and chronic liver disease, but the significance of this observation is unclear. There are several clinical tests which have been used to measure cellular immunity. In vivo skin testing to a variety of exogenous antigens such as DNCB has been widely used and depressed immunity has been shown to occur in chronic hepatitis (Toh et al, 1973), PBC (Fox et al, 1973) and alcoholic cirrhosis (Berenyi et al, 1974). This clinical index of cellular immunity has been replaced by in-vitro tests, lymphocyte transformation being the first and until recently, the most widely used technique. This can be used in one of two ways. Impaired lymphocyte tansformation in response to a non-specific mitogen such as phytohaemagglutinin (PHA)has been recognised as an index of depressed cellular immunity and this has been found in active chronic hepatitis (Toh et al, 1973) primary biliary cirrhosis (Mac Sween et al, 1973) alcoholic liver disease (Berenyi et al, 1974) and acute viral hepatitis both $\mathrm{HBsAg}$ positive and negative (Newble et al, 1975). This, however, is a non specific finding as impaired PHA transformation can be observed in a large number of non hepatic inflammatory disorders where it is little more than an index of systemic disease. Furthermore, its value as an index of $T$ cell function is questionable, since there is evidence to suggest that PHA may stimulate both $T$ and $B$ cells. The mechanism whereby lymphocyte transformation is impaired is unknown but a serum factor is probably involved, which raises further doubts about its specificity in relation to $\mathrm{T}$ cell function.

Lymphocyte transformation can also be used as an index of sensitisation to specific antigens. Thus Zetterman and Leevy (1975) have shown sensitisation to homogenates of autologous liver in patients with alcoholic hepatitis but not to other forms of alcoholic liver disease. The significance of this observation is uncertain since such a preparation contains a variety of antigens both specific and non-specific. Doubts about the validity of.lymphocyte transformation as an index of $\mathrm{T}$ cell function have led investigators to use the inhibition of leucocyte migration as the favoured test of cellular immunity. This test involves measurement of migration of peripheral leucocytes from a capillary tube into a culture medium containing the antigen under test and comparing it with a control tube in which the antigen is absent. Inhibition of migration is taken as evidence of delayed hypersensitivity, although some workers consider excessive stimulation as evidence of the same phenomenon. Using homogenates of liver tissue, impairment in cellular immunity has been demonstrated in both chronic active hepatitis and primary biliary cirrhosis (Bacon et al, 1972) as well as alcoholic hepatitis (Mihas et al, 1975) but not in alcoholic cirrhosis. Once again this system involves a heterogeneous assortment of tissue antigens but more recently this test has been examined using more specific antigens. Meyer zum Büschenfelde et al, 1979 have demonstrated sensitisation to liver-specific protein in $85 \%$ of auto-antibody positive and $30-45 \%$ of auto-antibody. 
negative patients with chronic active liver disease. Leevy et al (1976) have purified alcoholic hyaline and shown leucocyte migration inhibition to this antigen in patients with alcoholic hepatitis but not in patients with other forms of alcoholic liver disease. These interesting results are difficult to interpret because of the uncertain significance and specificity of the leucocyte migration test. Variable factors such as different techniques for isolating the leucocytes, difficulties in standardising antigen and choice of appropriate controls have resulted in problems in confirming these results. As with lymphocyte transformation, doubts have been raised as to whether this is a true test of cellular immunity and immune complexes have been shown experimentally to have a significant influence on migration (Kotkes and Pick, 1975). An alternative approach is to study the lymphocytes in both the serum and liver of patients with hepatic liver disease. Thomas et al (1976) have shown reduction in the peripheral $\mathrm{T}$ cell population in different forms of chronic liver disease, while De Horatius et al, 1974 have shown similar results in acute hepatitis. Since lymphocyte infiltration of the liver is commonly seen in chronic liver disease, it is tempting to suggest that the peripheral $\mathrm{T}$ cell depletion is related to the cells gathering in the liver. Preliminary attempts to isolate and characterise lymphocytes from liver biopsy material have encountered considerable technical problems.

\section{OTHER IMMUNOLOGICAL MECHANISMS}

\section{Immune complex disorders}

Immune complexes are now recognised as being capable of inducing immunologic tissue injury in many pathological conditions and liver disease is no exception. However, only a minority of such complexes are detrimental. Continuing antigen excess, low avidity antibody formation, complement activation and increased vascular permeability are all factors which induce immune complex disease. The liver is normally the site of complement production and it serves an important function in clearing immune complexes from the circulation although in cases of liver disease this ability is often impaired. Estimation of immune complexes in serum is difficult since a variety of tests are available which differ in principle and measure different phenomena. The role of hepatitis B surface antigen in immune complexes has been studied extensively by Trepo and colleagues (1979). They have shown a good correlation between many of the complications of the infection, such as glomerulonephritis, polyarteritis nodosa, cryoglobulinaemia, papular acrodermatitis (Gianotti's syndrome), arthritis and the presence of complexes. Interestingly in these patients the liver lesion is usually comparatively mild. Other investigators have examined complement metabolism in non-B liver disease. Increases in $\mathrm{C} 1 \mathrm{q}$ binding indicate that immune complexes have been shown in P.B.C. accompanied by increased catabolism of C3 and Thomas et al (1977) have suggested that these complexes may play a significant role in the pathogenesis of the disorder. The antigen which provokes formation of such complexes is unknown.

\section{Cytotoxicity}

A recent new development in in vitro immunological techniques has been the demonstration of specific cytotoxicity by lymphocytes against pure cell cultures. Lymphocytes from patients with chronic active hepatitis have been shown to be cytotoxic against a variety of target cells, including Chang liver cells (Wands et al, 1975) isolated human hepatocytes (Geubel et al, 1976) and rabbit hepatocytes (Thomson et al, 1974) and this can be blocked by liver specific lipoprotein. This however can also be 
shown in acure viral hepatitis (Paronetto and Vernace, 1975) and in alcoholic hepatitis (Kakumu and Leevy, 1975) and is not specific for liver inflammatory disorders. At present the mechanism for this phenomenon is not understood, neither is the significance in relation to the pathogenesis of acute and chronic liver disease.

\section{IMMUNOLOGICAL PHENOMENA ASSOCIATED WITH LIVER DISEASE}

\section{Chronic active bepatitis}

Immunological phenomena associated with chronic active hepatitis depend very much upon the aetiology of the liver disease. In patients with chronic aggressive hepatitis associated with hepatitis $B$ antigen, phenomena such as polyarteritis nodosa, arthritis and glomerulonephritis are known to occur secondary to immune complex deposition as discussed earlier. Rather different disturbances are found in the HBsAg-negative group. Gross elevations in serum globulins, especially IgG are frequently observed. As mentioned earlier, autoantibodies are often found in this group of patients, particularly high titre IgG class antinuclear and anti-smooth muscle antibodies. Some of these patients, both clinically and histologically resemble patients with primary biliary cirrhosis and this is reflected by the increased incidence of positive antimitochondrial antibodies. Extrahepatic manifestations, such as ulcerative colitis, pleurisy, myocarditis, Sjögren's syndrome, Hashimoto's thyroiditis and Cushing's syndrome are also unusually common in the $\mathrm{HBsAg}$ negative group. Renal tubular acidosis is commonly found in patients with both chronic active hepatitis and P.B.C. this has been attributed to the development of an immune response to Tamm-Horsfall glycoprotein which is induced by the release of cross-reacting antigens from damaged hepatocytes.

Increasing knowledge of the aetiology of chronic active hepatitis reveals that the HBsAg-negative group can be further subdivided. Thus, a number of drugs - notably Oxyphenisatin and Aldomet - have been implicated in the pathogenesis of chronic active hepatitis, both with and without the production of autoantibodies. Many of the autoantibody-negative chronic active hepatitis patients have been shown to suffer from metabolic disturbances such as alpha-1-antitrypsin deficiency or Wilson's disease, and in these patients the auto-immune phenomena are less commonly found. Chronic aggressive hepatitis may also be associated with agammaglobulinaemia (Good et al, 1960 ) suggesting that the disordered $B$ cell response is not primarily responsible for the progressive liver damage.

\section{Primary biliary cirrbosis}

Other immunological disorders are much less commonly associated with P.B.C. than with the auto-antibody positive chronic active hepatitis. However, $70 \%$ of these patients have evidence of the sicca complex of dry eyes and dry mouth although this is often asymptomatic. Less commonly there is an association with collagen disorders like scleroderma or the CRST syndrome of Calcinosis, Raynauds Phenomenon, Sclerodactyly and Telangiectasia (Reynolds et al, 1971).

The impairment in cell mediated immunity by both skin-testing and in vitro tests seems to be particularly marked in PBC. This condition is frequently characterised by the presence of granulomata within the liver and occasionally in other tissues, thus raising the possibility of its relationship to Crohn's disease or sarcoidosis, which may also be associated with anergic phenomena. In vitro tests, however, are known to be non-specific and more specific discriminants of these disorders have failed to date to reveal a common aetiology. 


\section{Genetic Factors in Liver Disease}

Our current knowledge of chronic liver disease suggests that certain individuals appear to be peculiarly susceptible to the development of some of these disorders. Only a minority of alcohol abusers develop chronic progressive liver disease, while the chronic hepatitis which occurs secondary to drugs such as Methyldopa and Oxiphenisatin is a sensitivity phenomenon which affects only a small minority of patients taking these medications. Serum auto-antibodies in high titre are found in less than $1 \%$ of the normal population for reasons which are unknown. The possibility that genetic factors might be important in liver disorders was stimulated by the finding that patients with auto-antibody positive chronic active hepatitis have a significantly increased incidence of HLA types A1 and B8 (MacKay and Morris, 1972). This has been confirmed by other workers and Vogten et al (1979) have in addition shown an association with Dw3 antigen and cell mediated immunity directed against liver specific protein. Although this is strong evidence in support of a genetic predisposition, there must be other facts involved in order to explain the marked female predominance of $\mathrm{HBsAg}$ negative chronic active hepatitis. Studies in $\mathrm{HBsAg}$ positive chronic active liver disease and in primary biliary cirrhosis have failed to show any associations with HLA type.

The position with regard to alcoholic liver disease is confused. In England Bailey and colleagues (1976) have reported an increased incidence of B8 but this has not been established by Scott et al (1977). Bell and Nordhagen (1978) have claimed an increased incidence of Bw40 in Norway while Melendez et al (1979) found high frequency of B13 in Chile. It is possible that some of these discrepancies are due to ethnic differences, but considerable caution must be exercised in interpreting the findings for several reasons. Statistical correction for the number of specificities studied is essential in evaluating the significance of such results. There must be very careful histological demonstration of the type of liver disease in all patients studied. Finally, great care must be taken in selecting appropriate control subjects.

\section{Therapy of liver disease}

The idea that many chronic liver diseases may be immunologically mediated has led to the use of drugs designed to suppress immune responses. This has been particularly successful in HBsAg negative chronic active hepatitis, particularly in patients with serum auto-antibodies where corticosteroids are highly effective in suppressing chronic inflammatory changes. Immunosuppressive drugs; of which azathiaprine is by far the most widely used, are valuable adjuncts to steroid therapy although of little use on their own. The effect of steroids in the treatment of $\mathrm{HBsAg}$ positive chronic active liver disease is much less certain, possibly reflecting a difference in aetiology of the disorder. In primary biliary cirrhosis both steroids and azathiaprine have been shown to be ineffective but penicillamine appears to be a promising new line of treatment. Although the drug has significant immunosuppressive properties as well as powerful effects on collagen metabolism, it may act by removing excessive liver copper which accumulates in this condition.

The effects of corticosteroids in suppressing the inflammatory response of alcoholic liver diseases have been conflicting. These studies, however, have included such a heterogeneous group of patients that it still seems. possible that somé patients with alcoholic hepatitis may benefit from steroids (Maddrey et al, 1978).

One hypothesis to explain the progressive nature of certain liver diseases assumes a failure of the phagocytic cells of the liver to eliminate the stimulus, whether it be a virus or other agent. If this is true, immunostimulants should be an effective form of therapy. Chadwick et al (1977) have used levamisole to treat patients with $\mathrm{HBs}$ Ag 
positive chronic active hepatitis. Although this resulted in significant changes in serum transaminases and in $\mathrm{HBsAg}$ antigen titre there was no evidence of resolution of infection. The probable effect of levamisole was to stimulate the liberation of hepatitis virus which then merely infected other hepatocytes and future studies combining an immunostimulant with an antiviral agent such as interferon (Greenberg et al, 1976) may be more effective.

Another therapeutic manoeuvre involving immunological mechanisms has been the use of transfer factor. This is a dialysable leucocyte extract which is stored in lymphocytes and is capable of transferring cellular immunity from a skin test positive donor to a skin test negative recipient. This has been used by several investigators (Redeker, 1979) in an attempt to treat HBsAg positive chronic liver disease and although changes in cell mediated immunity were demonstrable by the in vitro tests there was no important alteration in the transaminase levels or in HBsAg titre. Transfer factor is obtained from the lymphocytes of patients who have recovered from hepatitis $B$ infection and it may be that insufficient material was used, although transient increases in $\mathrm{HBsAg}$ titres and liver enzymes have usually been observed, implying some cytolytic effect.

\section{REFERENCES}

ARAKAWA Y, BULL DM, SCHOTT CF \& DAVIDSON CS: F-Antigen. Nature, liver specificity and release in experimental liver injury, Gastroent 71: 118, 1976.

BACON PA, BERRY H \& BOWN R: Cell-mediated immune reactivity in liver disease, Gut, 13: 427, 1972.

BAILEY RJ, KRASNER N, EDDLESTON AIWF, WILLIAMS R, TEE DEH, DONIACH D, KENNEDY LA \& BATCHEIOR JR: Histocompatibility antigens, autoantibodies and immunoglobulins in alcoholic liver disease, $B r$ Med $J$ ii: $726,1976$.

BELL H \& NORDHAGEN R: Association between HLA-BW $\mathbf{4 0}$ and alcoholic liver disease with cirrhosis, Br Med J i: 822, 1978.

BERENYI MR, STRAUS B \& AVILA L: T rosettes in alcoholic cirrhosis of the liver, J.A.M.A., 232: 44, 1974.

BIANCHI FB PENFOLD PL \& ROITT IM: Mitochondrial antibodies in primary biliary cirrhosis. V. Ultrastructural localisation of the antigen to the inner mitochondrial membranes using a direct peroxidase conjugate, Br J Exp Path 54: 652, 1973.

BJÖRNBOE M, PRYTZ H \& ORSKOV F: Antibodies to intestinal microbes in serum of patients with cirrhosis of the liver, Lancet, i: 58, 1972.

CANTOR HM \& DUMONT AE: Hepatic suppression of sensitisation to antigen absorbed into the portal system, Natwre, 215: 744, 1967.

CHADWICK RG, JAIN S, THOMAS HC \& SHERLOCK S: Levamisole in the treatment of HBs antigen positive chronic active liver disease, Gut, 18: A979, 1977.

DEHORATIUS RJ, STRICKLAND RG \& WILLIAMS RC Jr: T and B lymphocytes in acute and chronic hepatitis, Clin Immmunol Immunopatbol 2: 353, 1974.

DONIACH D, ROITT IM, WALKER JG \& SHERLOCK S: Tissue antibodies in primary biliary cirrhosis, active chronic hepatitis, cryptogenic cirrhosis and other liver diseases and their clinical implications, Clin Exp Immunol 1: 237, 1966.

FOURNIE GJ, LAMBERT PH \& MIESCHER PA: Release of DNA in circulating blood and induction of anti-DNA antibodies after injection of bacterial lipopolysaccharides. J Exp Med 140: 1189, 1974.

FOX RA, DUDLEY FJ \& SHERIOCK S: The primary immune response to haemocyanin in patients with primary biliary cirrhosis, Clin Exp Immunol, 14: 4731973.

FRANZI RE: The Primary Immune Response in Mice. III. Retention of sheep red blood cell immunogens by the spleen and liver, Infection and Immunity, 6: 469, 1972.

GAJDUSEK DC: An wauto-immune* reaction against human tissue antigens in certain chronic diseases, Nature, 179: 666, 1957.

GEUBEL AP, KELIFR RH, SUMMERSKILL WHJ, DICKSON ER, TOMASI TB \& SHORTER, RG: Lymphocyte cytotoxicity and inhibition studied with autologous liver cells: observations in chronic active liver disease and the primary biliary cirrhosis syndrome, Gastroent 71: 450, 1976.

GOOD RA \& PAGE AR: Fatal complications of virus hepatitis in two patients with agammaglobulinaemia, Amer J Med 29: 8041960.

GREENBERG HB, POLIARD RB, LUTWICK LI, GREGORY PB, ROBINSON WS, MERIGAN TC: Effect of human leucocyte interferon on Hepatitis B virus infection in patients with chronic active hepatitis, New Engl J Med 295: 517, 1976.

HASERICK JR, LEWIS LA \& BORTZ DW: Blood factor in acute disseminated lupus erythematosus. 1. Determination of gamma globulin as specific plasma fraction, Amer J Med Sci 219: 660, 1950. 
HAVENS WP, MEYERSON RM \& KLATCHKO J: Production of tetanus antitoxin by patients with hepatic cirrhosis. N Engl J Med 257: 637, 1957.

HAVENS WP, DICKENSHEETS J, BIERLY JN \& EBERHARD TP: The half-life of I13l labelled normal human gamma globulin in patients with hepatic cirrhosis. J lmmunol 73: 256, 1954.

JOHNSON GD, HOLBOROW EJ \& GLYNN LE: Antibody to smooth muscle in patients with liver disease. Lancet ii: 878, 1965.

KAKUMU S \& LEEVY CM: Lymphucyte cytotoxicity in alcoholic hepatitis, Gastroent 72: 594, 1977.

KINGHAM JGC, RASSAM S, GANGULY NK, MCGUIRE, MJ, NASRAT B, HOLGATE ST, TRIGER DR \& WRIGHT R: D.N.A.-binding antibodies and hepatitis $B$ markers in acute and chronic liver disease, Clin Exp Immunol 33: 204, 1978.

KLATSKIN G \& KANTOR FS: Mitochondrial antibody in Primary Biliary cirrhosis and other diseases, $A n n$ Int Med 77: 533, 1972.

KOTKES P \& PICK E: Studies on the inhibition of macrophage migration induced by soluble antigen-antibody complexes, Clin Exp Immunol 19: 105, 1975.

LAM KC, MISTILIS SP \& PERROTT N: Positive tissue antibody tests in patients with prolonged extrahepatic biliary obstruction, $N$ Engl J Med 286: 1400, 1972.

LEEVY CM, CHEN T, LUISADA-OPPER A, KANAGASUNDARAM N \&ZETTERMAN R: Liver disease of the alcoholic: Role of immunologic abnormalities in pathogenesis, in: Progress in Liver Diseases, Vol. 5, eds Popper, H. and Schaffner, F. Grune and Stratton. New York pp. 516, 1976.

LIDMAN K, BIBERFELD G, FAGRAEUS A, NORBERG R, TORSTENSSON R, UTTER G, CARLSSON L, LUCA J \& LINDBERG U: Anti-actin specificity of human smooth muscle antibodies in chronic active hepatitis, Clin Exp Immunol 24: 266, 1976,

MACKAY IR \& MORRIS PJ, Association of autoimmune active chronic hepatitis with HL-A1, 8, Lancet, ii: 793, 1972.

MACSWEEN RNM, GALBRAITH I, THOMAS MA, WATKINSON G \& LUDLAM G B:Phytohaemagglutinin (PHA) induced lymphocyte transformation and Toxoplasma gondii antibody studies in primary biliary cirrhosis. Evidence of impaired cell-mediated immunity, Clin Exp Immunol 15: 35, 1973.

MADDREY WC, BOITNOTT JK,BEDINE MS WEBER FL MEZEY E \& WHITE RI: Corticosteroid therapy of alcoholic hepatitis. Gastroent 75: 193, 1978.

MELENDEZ M, VARGAS-TANK L, FUENTES C, ARMAS-MERINO R, CASTILLO D, WOLFF C, WEGMANN, ME \& SOTO R: Distribution of HLA histocompatibility antigens, ABO blood groups and $\mathrm{Rh}$ antigens in alcoholic liver disease, Gut, 20: 288, 1979.

MEYER ZUM BÜSCHENFELDE, KH, KOSSLING FK \& MIESCHER PA: Experimental chronic active hepatitis in rabbits following immunisation with human liver proteins, Clin Exp Immunol 11: 99, 1972.

MEYER ZUM BÜSCHENFELDE, KH \& HUTTEROTH TH: Auto-antibodies against liver membrane antigens in chronic active liver disease, in: Immune Reactions in Liver Disease. Eds. Eddleston, A.L.W.F., Weber, J.C.P. and Williams, R Pitman Medical. p. 12, 1979.

MIHAS, AA, BULL DM, \& DAVIDSON CS: Cell-mediated immunity to liver in patients with alcoholic hepatitis, Lancet, i: $951,1975$.

NEWBLE DI,HOLMES KT, WANGEL AG, \& FORBES IJ: Immune reactions in acute viral hepatitis. Clin Exp Immunol, 20: 17, 1975.

PARONETTO F \& VERNACE S: Immunological studies in patients with chronic active hepatitis: cytotoxic activity in lymphocytes to autochthonous liver cells grown in tissue culture, Clin Exp Immun 19:99, 1975.

PROTELL RL, SOLOWAY RD, MARTIN WJ, SCHOENFIELD LJ \& SUMMERSKILL WHJ: Anti-salmonella agglutinins in chronic active liver disease, Lancet, ii: 330, 1971.

RAVIN HA, ROWLEY D, JENKINS C \& FINE J: On the absorption of bacterial endotoxin from the gastro-intestinal tract of the normal and shocked animal, $J$ Exp Med, 112: 783, 1960.

REDEKER AG: Transfer factor in $\mathrm{HBsAg}$ positive patients in: Immune Reactions in Liver Disease, Eds. Eddleston, A.L.W.F., Weber, J.C.P. and Williams, R. p. 275, Pitman, 1979.

REYNOLDS TB, DENISON EK, FRANKL HD, LIEBERMAN FL \& PETERS RL: Primary biliary cirrhosis with scleroderma, Raynaud's phenomenon and telangiectasia. Amer J Med 50: 302, 1971.

RIZZETTO, M, SWANA G \& DONIACH D: Microsomal antibodies in active chronic hepatitis and other disorders, Clin Exp Immunol 15: 331, 1973.

RODRIGUEZ M, PARONETTO F, SCHAFFNER F \& POPPER H: Antimitochondrial antibodies in jaundice following drug administration, J.A.M.A., 208: 148, 1969.

SCOTT, BB, RAJAH SM, \& LOSOWSKY M: Histocompatibility antigens in chronic liver disease, Gastroent, 72: $122,1977$.

SELL S \& FAHEY JL: Relationship between gamma-globulin metabolism and low serum gamma-globulin in germ-free mice, J. Immunol 93: 81, 1964.

SOUHAMI RL: The effect of Colloidal carbon on the organ distribution of sheep red cells and the immune response, Immunology, 22: 685, 1972.

SWARBRICK ET, STOKES CR \& SOOTHILL JF: Absorption of antigens after oral immunisation and simultaneous inductions of specific systemic tolerance, Gut, 20: 121, 1979.

SUGAMARA K \& SMITH JB: Purification and characterisation of human liver specific $\mathrm{F}$ antigen, Clin Exp Immunol, 26: 28, 1976. 
TAGE-JENSEN J, ARNOLD W, DIETRICHSON O, HARDT F, HOPF U, MEYER ZUM BUSCHENFELDE K H \& NIELSEN JO: Liver cell membrane autoantibody specific for inflammatory liver diseases, Br Med J i: 206, 1977.

THOMAS HC MACSWEEN, RNM \& WHITE RG: Role of the liver in controlling the immunogenicity of commensal bacteria in the gut, Lancet, i: $1288,1973$.

THOMAS HC, FRENI M, SANCHEZ-TAPIAS J, DE VILLIERS DJAIN S \& SHERLOCK S: Peripheral blood lymphocyte populations in chronic liver disease, Clin Exp Immunol, 26: 222, 1976.

THOMAS HC, POTTER BJ \& SHERLOCK S: Is Primary Biliary Cirrhosis an immune complex disease? Lancet, ii: $1261,1977$.

THOMSON AD, COCHRANE MAG, MACFARLANE IG, EDDLESTON ALWF \& WILLIAMS R: Lymphocyte cytotoxicity to isolated hepatocytes in chronic active hepatitis, Nature, 252: 721, 1974.

TOH, BH, ROBERTS-THOMSON IC, MATHEWS JD, WHITTINGHAM S, MACKAY IR: Depression of cell-mediated immunity in old age and the immunopathic diseases, lupus erythematosus, chronic hepatitis and rheumatoid arthritis, Clin Exp Immunol, 14: 193, 1973.

TONG MJ, NIES KM, REYNOLDS TB \& QUISMORIO F: Immunological studies in familial primary biliary cirrhosis, Gastroent, 71: 305, 1976.

TREPO C, REVILLARD JP \& BERTHOUX F: Immune complexes and pathogenesis of hepatitis B virus infections, in: Immune Reactions in Liver Disease, eds. Eddleston, A.L.W.F., Weber, J. C. P. and Williams, R. Pitman Medical, pp. 69, 1979.

TRIGER DR, ALP MH \& WRIGHT R: Bacterial and dietary antibodies in liver disease, Lancet, i: 60, 1972.

TRIGER DR \& WRIGHT R: Studies on the hepatic uptake of antigen. II The effect of hepatotoxins on the immune response, Immunology, 25: 951, 1973.

TRIGER DR, CYNAMON MH \& WRIGHT R: Studies on the hepatic uptake of antigen. I. Comparison of inferior vena cava and portal vein routes of immunization. Immunology, 25: 941, 1973.

TRIGER DR, KURTZ JB \& WRIGHT R: Viral antibodies and autoantibodies in chronic liver disease, Gut, 15: 94, 1974.

TRIGER DR, BOYER TD,WAXMAN AD, REDEKER AG \& REYNOLDS TB: Differences in intra-hepatic portal-systemic shunting in alcoholic and non alcoholic liver disease as assessed by liver scan, portal pressure and E. coli antibodies. Dig Dis Sci, 24: 509, 1979.

WALKER JG, BATES D, DONIACH D, BALI PAJ \& SHERLOCK S: Chronic liver disease and mitochondrial antibodies. A family study. Br Med $J$, i: $146,1972$.

WANDS JR, PERROTTO JL, ALPERT E \& ISSELBACHER KJ: Cell-mediated immunity in acute and chronic hepatitis, J Clin Invest 55: 921, 1975.

VOGTEN AJM, SHORTER RG \& OPELZ G: HLA and cell-mediated immunity in HBsAg negative chronic active hepatitis, Gut, 20: 523, 1979.

WARSHAW, AL, WALKER WA \& ISSELBACHER KJ: Protein uptake by the intestine: evidence for absorption of intact macromolecules, Gastroent, 66: 987, 1974.

WISSE E: Ultrastructure and Function of Kupffer cells and other sinusoidal cells in the liver, in: Kupffer Cells and Other Liver Sinusoidal Cells, eds. Wisse, E. and Knook, D. L. pp. 33, 1977. Amsterdam: Elsevier/ /North Holland Biomedical Press.

ZETTERMAN RK \& LEEVY CMM: Immunologic reactivity and alcoholic liver disease, Bull N Y Acad Med. 51: $533,1975$.

Address for reprints: David $R$. Triger

Department of Medicine

Floor $M$

Hallamshire Hospital

Sheffield S10 $2 \mathrm{JF}$

England 